\title{
Safety and effectiveness of SGM-101, a fluorescent antibody targeting carcinoembryonic antigen, for intraoperative detection of colorectal cancer
}

Citation for published version (APA):

Boogerd, L. S. F., Hoogstins, C. E. S., Schaap, D. P., Kusters, M., Handgraaf, H. J. M., van der Valk, M. J. M., Hilling, D. E., Holman, F. A., Peeters, K. C. M. J., Mieog, J. S. D., de Velde, C. J. H. V., FarinaSarasqueta, A., van Lijnschoten, I., Framery, B., Pelegrin, A., Gutowski, M., Nienhuijs, S. W., de Hingh, I. H. J. T., Nieuwenhuijzen, G. A. P., ... Vahrmeijer, A. L. (2018). Safety and effectiveness of SGM-101, a fluorescent antibody targeting carcinoembryonic antigen, for intraoperative detection of colorectal cancer: a dose-escalation pilot study. The Lancet Gastroenterology and Hepatology, 3(3), 181-191. https://doi.org/10.1016/S2468-1253(17)30395-3

Document status and date:

Published: 01/03/2018

DOI:

10.1016/S2468-1253(17)30395-3

Document Version:

Publisher's PDF, also known as Version of record

\section{Document license:}

Taverne

Please check the document version of this publication:

- A submitted manuscript is the version of the article upon submission and before peer-review. There can be important differences between the submitted version and the official published version of record.

People interested in the research are advised to contact the author for the final version of the publication, or visit the DOI to the publisher's website.

- The final author version and the galley proof are versions of the publication after peer review.

- The final published version features the final layout of the paper including the volume, issue and page numbers.

Link to publication

\footnotetext{
General rights rights.

- You may freely distribute the URL identifying the publication in the public portal. please follow below link for the End User Agreement:

www.umlib.nl/taverne-license

Take down policy

If you believe that this document breaches copyright please contact us at:

repository@maastrichtuniversity.nl

providing details and we will investigate your claim.
}

Copyright and moral rights for the publications made accessible in the public portal are retained by the authors and/or other copyright owners and it is a condition of accessing publications that users recognise and abide by the legal requirements associated with these

- Users may download and print one copy of any publication from the public portal for the purpose of private study or research.

- You may not further distribute the material or use it for any profit-making activity or commercial gain

If the publication is distributed under the terms of Article $25 \mathrm{fa}$ of the Dutch Copyright Act, indicated by the "Taverne" license above,

Download date: 26 Apr. 2023 


\title{
Safety and effectiveness of SGM-101, a fluorescent antibody targeting carcinoembryonic antigen, for intraoperative detection of colorectal cancer: a dose-escalation pilot study

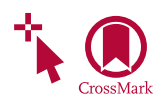

\author{
Leonora S F Boogerd*, Charlotte ES Hoogstins*, Dennis P Schaap, Miranda Kusters, Henricus J M Handgraaf, Maxime J M van der Valk, \\ Denise E Hilling, Fabian A Holman, Koen C M J Peeters, J Sven D Mieog, Cornelis J H van de Velde, Arantza Farina-Sarasqueta, Ineke van Lijnschoten, \\ Bérénice Framery, André Pèlegrin, Marian Gutowski, Simon W Nienhuijs, Ignace HJT de Hingh, Grard A P Nieuwenhuijzen, Harm JT Rutten, \\ Francoise Cailler, Jacobus Burggraaf, Alexander L Vahrmeijer
}

\section{Summary}

Background Tumour-targeted fluorescence imaging has the potential to advance current practice of oncological surgery by selectively highlighting malignant tissue during surgery. Carcinoembryonic antigen (CEA) is overexpressed in $90 \%$ of colorectal cancers and is a promising target for colorectal cancer imaging. We aimed to assess the tolerability of SGM-101, a fluorescent anti-CEA monoclonal antibody, and to investigate the feasibility to detect colorectal cancer with intraoperative fluorescence imaging.

Methods We did an open-label, pilot study in two medical centres in the Netherlands. In the dose-escalation cohort, we included patients (aged $\geq 18$ years) with primary colorectal cancer with increased serum CEA concentrations (upper limit of normal of $\geq 3 \mathrm{ng} / \mathrm{mL}$ ) since diagnosis, who were scheduled for open or laparoscopic tumour resection. In the expansion cohort, we included patients (aged $\geq 18$ years) with recurrent or peritoneal metastases of colorectal cancer, with increasing serum concentrations of CEA since diagnosis, who were scheduled for open surgical resection. We did not mask patients, investigators, or anyone from the health-care team. We assigned patients using a $3+3$ dose design to $5 \mathrm{mg}, 7.5 \mathrm{mg}$, or $10 \mathrm{mg}$ of SGM-101 in the dose-escalation cohort. In the expansion cohort, patients received a dose that was considered optimal at that moment of the study but not higher than the dose used in the dose-escalation cohort. SGM-101 was administered intravenously for $30 \mathrm{~min}$ to patients 2 or 4 days before surgery. Intraoperative imaging was done to identify near-infrared fluorescent lesions, which were resected and assessed for fluorescence. The primary outcome was tolerability and safety of SGM-101, assessed before administration and continued up to $12 \mathrm{~h}$ after dosing, on the day of surgery, the first postoperative day, and follow-up visits at the day of discharge and the first outpatient clinic visit. Secondary outcomes were effectiveness of SGM-101 for detection of colorectal cancer, assessed by tumour-to-background ratios (TBR); concordance between fluorescent signal and tumour status of resected tissue; and diagnostic accuracy in both cohorts. This trial is registered with the Nederlands Trial Register, number NTR5673, and ClinicalTrials.gov, number NCT02973672.

Findings Between January, 2016, and February, 2017, 26 patients (nine in the dose-escalation cohort and 17 in the expansion cohort) were included in this study. SGM-101 did not cause any treatment-related adverse events, although three possibly related mild adverse events were reported in three (33\%) of nine patients in the dose-escalation cohort and five were reported in three (18\%) of 17 patients in the expansion cohort. Five moderate adverse events were reported in three (18\%) patients in the expansion cohort, but they were deemed unrelated to SGM-101. No changes in vital signs, electrocardiogram, or laboratory results were found after administration of the maximum dose of $10 \mathrm{mg}$ of SGM-101 in both cohorts. A dose of $10 \mathrm{mg}$, administered 4 days before surgery, showed the highest TBR (mean TBR 6.10 [SD 0.42] in the dose-escalation cohort). In the expansion cohort, 19 (43\%) of 43 lesions were detected using fluorescence imaging and were not clinically suspected before fluorescent detection, which changed the treatment strategy in six (35\%) of 17 patients. Sensitivity was $98 \%$, specificity was $62 \%$, and accuracy of fluorescence intensity was $84 \%$ in the expansion cohort.

Interpretation This study presents the first clinical use of CEA-targeted detection of colorectal cancer and shows that SGM-101 is safe and can influence clinical decision making during the surgical procedure for patients with colorectal cancer.

Funding Surgimab.

\section{Introduction}

A new era in the field of near-infrared fluorescenceguided oncological surgery has commenced with the first clinical studies using tumour-specific fluorescent tracers. ${ }^{1}$ Fluorescence imaging can provide surgeons with real-time feedback about the location and extent of tumours, which might increase radical resection rates and improve patient outcomes. This technology uses
Lancet Gastroenterol Hepato 2018; 3: 181-91 Published Online January 17,2018 http://dx.doi.org/10.1016/ S2468-1253(17)30395-3 See Comment page 147

${ }^{*}$ Contributed equally

Department of Surgery (LS F Boogerd MD CE S Hoogstins MD, $M$ Kusters MD, HJ M Handgraaf MD, M J M van der Valk MD, D E Hilling MD, F A Holman MD, KCM J Peeters MD, JSD Mieog MD Prof CJ H van de Velde MD A L Vahrmeijer MD) and Department of Pathology (A Farina-Sarasqueta MD), Leiden University Medical Center, Leiden, Netherlands Department of Surgery, Catharina Hospital Eindhoven Eindhoven, Netherlands (D P Schaap MD, M Kusters, SW Nienhuijs MD, IHJT de Hingh MD, G A P Nieuwenhuijzen MD, Prof HJT Rutten MD); Stichting PAMM, Eindhoven, Netherlands (I van Lijnschoten MD): SurgiMab, Montpellier, France (B Framery MSc, F Cailler PhD); IRCM, Institut de Recherche en Cancérologie de Montpellier, Montpellier, France (A Pèlegrin PhD); INSERM, U1194, Montpellier, France (A Pèlegrin); Université de Montpellier, Montpellier, France (A Pèlegrin); Institut régional du Cancer de Montpellier, ICM, Montpellier, France (A Pèlegrin, M Gutowski MD); GROW, School Of Oncology and Developmental Biology, University of Maastricht Maastricht, Netherlands (Prof H JT Rutten); Centre for Human Drug Research, Leiden, Netherlands 
(Prof J Burggraaf MD); and Leiden Academic Center for Drug Research, Leiden, Netherlands (Prof J Burggraaf) Correspondence to: Dr Alexander L Vahrmeijer, Department of Surgery, Leiden University Medical Center, 2300 RC Leiden, Netherlands a.l.vahrmeijer@lumc.nl

\section{Research in context}

\section{Evidence before this study}

Tumour-targeted intraoperative fluorescence imaging can provide surgeons with real-time feedback about the location and extent of tumours, which might improve patient outcomes. A well known tumour marker for colorectal cancer is carcinoembryonic antigen (CEA), which is overexpressed in the vast majority of colorectal cancer cells. Involvement of surgical margins $(\mathrm{R}+)$ is reported in up to $28 \%$ of primary colorectal cancer resections and up to $50 \%$ of recurrent rectal cancer resections. Moreover, $10 \%$ of patients with colorectal cancer develop peritoneal metastases, for whom cytoreductive surgery with hyperthermic intraperitoneal chemotherapy is the recommended surgical procedure. The extent of cytoreduction is directly associated with survival; therefore, maximal cytoreduction of small and otherwise undetected tumour lesions is important. CEA-targeted fluorescence imaging can be of added value in both locoregional and metastasised colorectal cancer. Our preclinical studies showed that a fluorescent anti-CEA monoclonal antibody, SGM-101, binds to CEA-positive tumours and its metastases after intravenous administration.

\section{Added value of this study}

This study describes the first clinical application of SGM-101 in patients with colorectal cancer for intraoperative detection of primary, recurrent, and peritoneal metastases. We showed that intravenous administration of $10 \mathrm{mg}$ of SGM-101 in patients with colorectal cancer is safe and tolerable, with the sensitivity needed to detect malignant lesions that would have otherwise been missed during surgery. Importantly, SGM-101 allowed detection of both superficially and more deeply seeded metastases. This study also suggests that intraoperative fluorescence imaging might guide surgeons to identify areas from which frozen sections should be obtained for intraoperative decision making.

\section{Implications of all the available evidence}

Application of CEA-targeted fluorescence imaging during colorectal cancer surgery can result in improved demarcation and detection of otherwise undetected malignant lesions. Although investigated in a small pilot study, SGM-101 can influence perioperative clinical decision making. Larger studies are needed to assess whether improved colorectal cancer detection influences $\mathrm{RO}$ resection rates and results in more complete cytoreductive surgery, which should ultimately improve oncological outcomes. clinically available monoclonal antibodies (eg, bevacizumab or cetuximab) or new tumour-specific ligands that are conjugated to a fluorophore and accumulate in tumours after intravenous administration. ${ }^{2}$ Subsequently, a dedicated near-infrared fluorescence imaging system enables detection of tumours in real-time during the procedure. Several tumour-targeted tracers have been tested in first-in-human studies, yielding promising results for intraoperative fluorescence detection of ovarian cancer, head and neck cancer, breast cancer, and peritoneal metastases of colorectal cancer. ${ }^{3-6}$ However, no tracers have been investigated for fluorescence imaging of primary and recurrent colorectal cancer, although major advantages can be expected from this application.

The primary curative treatment for colorectal cancer is radical resection with clear margins (R0). Involvement of surgical margins $(\mathrm{R}+)$ is a poor prognostic factor for disease-free survival and overall survival, but is still reported in up to $28 \%$ of rectal cancer cases. ${ }^{7.8}$ In surgery for recurrent rectal cancer, an R0 resection is equally essential; this is generally achieved in $50-60 \%$ of cases, with 5 -year survival up to $70 \% .^{9}$ However, these procedures are challenging because of distorted pelvic anatomy after previous resections, the presence of multifocal tumour tissue, and difficulty in distinction between fibrosis and tumour tissue after neoadjuvant therapy..$^{10}$ Globally, $10 \%$ of patients with colorectal cancer develop peritoneal metastases, for whom cytoreductive surgery with hyperthermic intraperitoneal chemotherapy is the recommended therapy, resulting in median overall survival of up to 32 months. ${ }^{11}$ The extent of cytoreduction is directly associated with survival; therefore, maximal cytoreduction of the numerous and often small tumour lesions is pivotal. ${ }^{12}$ With its potential to highlight small tumour lesions, tumour-targeted fluorescence-guided surgery can be of added value in both locoregional and metastasised colorectal cancer. Moreover, it could aid distinction between fibrosis and malignant tissue, which is often challenging in patients with rectal cancer who have had chemotherapy and re-irradiation or irradiation therapy.

Carcinoembryonic antigen (CEA) is a well known tumour marker and is highly expressed in colorectal cancer. $^{13,14}$ Importantly, CEA expression in healthy tissue is on average 60 times lower than in tumour tissue, and the antigenic concentration of CEA on the surface of cancer cells is relatively high $\left(10^{5}-10^{6}\right.$ antigens per cell).$^{15}$ In this study, we describe SGM-101, a CEA-specific chimeric antibody conjugated to a fluorophore that emits near-infrared fluorescence. Preclinical studies showed that SGM-101 binds to CEA-positive colorectal cancer cells and its metastases after intravenous administration. ${ }^{16}$ On the basis of these promising results with SGM-101, translation in a clinical study in patients with colorectal cancer is a logical next step. Therefore, in this study, we aimed to assess the tolerability of ascending doses of SGM-101 in patients with primary colorectal cancer, and to determine the best performing dose and dosing time for intraoperative fluorescence imaging. Additionally, these parameters were used in an expansion cohort of patients with colorectal cancer for intraoperative 
detection of recurrent tumours, including peritoneal metastases, and to assess whether SGM-101 could change patient management.

\section{Methods}

\section{Study design and patients}

We did an open-label, pilot study in two centres (Leiden University Medical Center, Leiden; and the Catharina Hospital Eindhoven, Eindhoven) in the Netherlands. We used a $3+3$ dose escalating study design for those in the dose-escalation cohort only. This study was done in accordance with the Good Clinical Practice guidelines from the International Council for Harmonisation of Technical Requirements for Pharmaceuticals for Human Use, and the laws and regulations on drug research in humans of the Netherlands. The study was approved by a certified medical ethics review board (BEBO, Assen, Netherlands).

We included patients aged 18 years or older with a clinical diagnosis of primary colorectal cancer, with increased serum CEA concentrations ( $\geq$ upper limit of normal [ULN] of $\geq 3 \mathrm{ng} / \mathrm{mL}$ ), who were scheduled for either open or laparoscopic surgical resection in the dose-escalation cohort. Additionally, we included patients aged 18 years or older who were diagnosed with recurrent or peritoneal metastases of colorectal cancer, with increasing serum CEA concentrations since diagnosis, and who were scheduled for open surgical resection in the expansion cohort. Staging of primary colon and rectal cancers was done according to standard protocol and included CT or MRI, or both. Staging of recurrent colon and rectal cancers, as well as peritoneal metastases, was done with use of either CT, MRI, or, when considered necessary, with PET-CT. No patients were excluded on the basis of preoperative imaging, but only patients eligible for surgical resection were included.

We excluded patients who were pregnant or breastfeeding, had a history of anaphylactic allergic reactions, had a serum CEA concentration of $300 \mathrm{ng} / \mathrm{mL}$ or more, had a diagnosis of another malignancy within the past 5 years (except adequately treated in-situ carcinoma of the cervix and basal or squamous cell skin carcinoma), and had anticancer therapy (except for routine preoperative radiotherapy for colorectal cancer) within 4 weeks before inclusion. Additionally, we excluded patients with only colorectal cancer who had abnormal laboratory test values for aspartate aminotransferase, alanine aminotransferase, $\gamma$-glutamyltransferase, or alkaline phosphatase concentrations that were more than five times the ULN; and total bilirubin concentrations more than two times the ULN. We excluded patients who had abnormal laboratory test values for serum creatinine concentrations more than 1.5 times the ULN, absolute neutrophil counts less than $1.5 \times 10^{9}$ cells per $\mathrm{L}$, platelet counts less than $100 \times 10^{9}$ cells per L, or haemoglobin concentrations less than $4 \mathrm{mmol} / \mathrm{L}$ in women or $5 \mathrm{mmol} / \mathrm{L}$ in men. We also excluded patients with a known positive test for HIV infection, hepatitis B surface antigen, or hepatitis $C$ virus antibody; patients with untreated serious infections; and those who had any condition that the investigator considered to be potentially compromising to the patients' wellbeing or the study objectives. Participants gave written informed consent to the investigators before screening to take part in the study.

\section{Procedures}

In the dose-escalation cohort, we assigned patients using a $3+3$ dose design to $5 \mathrm{mg}, 7 \cdot 5 \mathrm{mg}$, or $10 \mathrm{mg}$ of SGM-101. In the expansion cohort, patients received a dose that was considered optimal at that moment of the study but not higher than the dose used in the dose-escalation cohort. We did not mask patients, investigators, or anyone from the health-care team and did not use placebo treatment.

SGM-101 consists of a chimeric monoclonal antibody that targets CEA covalently bound to the fluorophore BM-104. The tracer was manufactured by Novasep (Gosslies, Belgium) and supplied by Surgimab (Montpellier, France). Additional information about SGM-101 is provided in the appendix (p 1). On the basis of preclinical data, ${ }^{16}$ a dose-escalation scheme of SGM-101 (5 mg, $7.5 \mathrm{mg}$, or $10 \mathrm{mg}$ ) was used (appendix p 1). We intravenously infused patients with SGM-101 for $30 \mathrm{~min}$ in a dedicated clinical research unit at least 2 days before surgery. Following each dose level, the collected data (ie, safety data and fluorescence intensity of tumour and background tissue using that dose of SGM-101) were reviewed jointly by the investigator and sponsor before ascending the dose level.

All surgical procedures were done by experienced oncological surgeons. First, the surgical field was explored using standard visual and tactile methods (for which tactile methods were done only during open surgery). Subsequently, the fluorescence imaging, which was done with the Artemis and Spectrum fluorescence imaging system (Quest Medical Imaging, Middenmeer, Netherlands; appendix p 1), ${ }^{17}$ was used to identify near-infrared fluorescent lesions. All lesions identified by visual and tactile methods or near-infrared fluorescence imaging were resected if it was surgically feasible and supported a clinical purpose (eg, adjustment in staging or treatment). If resection included surrounding structures, a frozen section was first assessed by an attending pathologist to confirm whether resection was needed. Each resected lesion was marked on a case report form as fluorescent or non-fluorescent, and as either clinically suspected for malignancy or not.

Following resection, fluorescence imaging of the wound bed was done to identify any remaining fluorescence. Fluorescence imaging of the resection specimen was done in the operating room and the pathology department. All resected specimens were assessed for fluorescence both before and after slicing, and localisation of fluorescence signal was recorded on 


\begin{tabular}{|c|c|c|}
\hline & $\begin{array}{l}\text { Dose-escalation } \\
\text { cohort }(n=9)\end{array}$ & $\begin{array}{l}\text { Expansion } \\
\text { cohort }(n=17)\end{array}$ \\
\hline \multicolumn{3}{|l|}{ Sex } \\
\hline Men & $5(56 \%)$ & $10(59 \%)$ \\
\hline Women & $4(44 \%)$ & $7(41 \%)$ \\
\hline Median age (IQR; years) & $69(65-72)$ & $62(55-67)$ \\
\hline $\begin{array}{l}\text { Median preoperative concentration } \\
\text { of serum CEA }(\mathrm{IQR} ; \mathrm{ng} / \mathrm{mL})\end{array}$ & $4 \cdot 0(3 \cdot 0-5 \cdot 6)$ & $4 \cdot 3(1 \cdot 9-19 \cdot 7)$ \\
\hline \multicolumn{3}{|l|}{ Neoadjuvant therapy } \\
\hline Yes & $6(67 \%)$ & $14(82 \%)$ \\
\hline No & $3(33 \%)$ & $3(18 \%)$ \\
\hline \multicolumn{3}{|l|}{ Type of surgery } \\
\hline Abdominoperineal resection & $2(22 \%)$ & NA \\
\hline Low anterior resection & $4(44 \%)$ & NA \\
\hline Sigmoid resection & $2(22 \%)$ & NA \\
\hline Hemicolectomy & $1(11 \%)$ & NA \\
\hline \multicolumn{3}{|l|}{ Tumour recurrence locations } \\
\hline Anastomotic recurrence & NA & $2(12 \%)$ \\
\hline Lateral recurrence* & NA & $3(18 \%)$ \\
\hline Unifocal recurrence elsewhere† & NA & $4(24 \%)$ \\
\hline $\begin{array}{l}\text { Multifocal recurrence in small } \\
\text { pelvis }\end{array}$ & NA & $4(24 \%)$ \\
\hline Peritoneal recurrence & NA & $4(24 \%)$ \\
\hline \multicolumn{3}{|l|}{ Method of surgery } \\
\hline Open & $4(44 \%)$ & $16(94 \%)$ \\
\hline Laparoscopic & $4(44 \%)$ & 0 \\
\hline Transanal inspection & $1(11 \%)$ & $1(6 \%)$ \\
\hline \multicolumn{3}{|l|}{ Additional intraoperative therapy } \\
\hline Liver resection & $1(11 \%)$ & 0 \\
\hline Intraoperative radiotherapy & 0 & $10(59 \%)$ \\
\hline $\begin{array}{l}\text { Hyperthermic intraperitoneal } \\
\text { chemotherapy }\end{array}$ & 0 & $4(24 \%)$ \\
\hline \multicolumn{3}{|l|}{ Tumour stage } \\
\hline TO & $2(22 \%)$ & NA \\
\hline $\mathrm{T} 1$ & $1(11 \%)$ & NA \\
\hline $\mathrm{T} 2$ & $1(11 \%)$ & NA \\
\hline T3 & $5(56 \%)$ & NA \\
\hline $\mathrm{T} 4$ & 0 & NA \\
\hline \multicolumn{3}{|l|}{ Nodal stage } \\
\hline No & $5(56 \%)$ & NA \\
\hline N1 & $2(22 \%)$ & NA \\
\hline $\mathrm{N} 2$ & $2(22 \%)$ & NA \\
\hline
\end{tabular}

Data are $n(\%)$, unless otherwise specified. CEA=carcinoembryonic antigen. $\mathrm{NA}=$ not applicable. ${ }^{*}$ Tumours defined as a lateral recurrence were located in the obturator compartment or around the iliac vessels. TTumours defined as unifocal recurrence elsewhere in the abdomen were located near the duodenal curve, between the bladder and prostate, in the rectovaginal septum, or near the left iliopsoas muscle.

Table 1: Patient and tumour characteristics

macroscopic photographs. The slice containing the peak fluorescence signal of each patient undergoing surgery at the Leiden University Medical Center was additionally imaged with the Pearl imager (LI-COR Biosciences, Lincoln, NE, USA) to obtain ex-vivo tumour-to-background ratios (TBRs).
Additionally, we did tolerability assessments (ECG, blood pressure, pulse, peripheral oxygen saturation, respiratory rate, and temperature) at regular intervals starting directly before administration and continued up to $12 \mathrm{~h}$ after dosing. We repeated these measurements on the day of surgery, the first postoperative day, and the day of discharge from the hospital. Follow-up visits coinciding with clinical care took place at the day of discharge and the first outpatient clinic visit. Additionally, we recorded adverse events and the concomitant use of other medications throughout the study period. We also collected blood samples from participating patients before and after dosing of SGM-101, and serum CEA concentrations were measured in these samples.

An experienced board-certified gastrointestinal pathologist did routine assessment of tumour status on all resected lesions following haematoxylin and eosin staining. The histopathological examination was considered the reference standard. Tumour status was correlated with the status of fluorescence, and immunohistochemistry staining was done to directly correlate CEA expression to fluorescence signal in formalin-fixed paraffin-embedded (FFPE) blocks with use of the Pearl imager (appendix pp 2, 3). A fluorescent lesion that was tumour positive was considered a true positive, a fluorescent lesion that was tumour negative was considered a false positive, and a non-fluorescent lesion that was tumour positive was considered a false negative. Using these classifications, we also evaluated sensitivity, which was calculated by dividing the number of true-positive lesions by the total number of resected tumour lesions; and specificity, which was calculated by dividing the true-negative lesions by the total number of resected lesions without tumour involvement. Additionally, we evaluated the positive predictive value, which was calculated by dividing the number of true positives by the total number of true and false positives; and the negative predictive value, which was calculated by dividing the true-negative lesions by the total number of true and false-negative lesions.

\section{Outcomes}

The primary outcome was tolerability and safety of SGM-101, which was assessed with the use of routine clinical measures such as treatment-related adverse events, blood pressure, heart rate, body temperature, peripheral oxygen saturation, respiratory rate, skin examination, and routine laboratory assessments. Treatment-related adverse events were defined as any adverse event associated with the study procedure but not necessarily related to the study intervention (ie, SGM-101) for up to 10 days after surgery, using the National Cancer Institute Common Terminology Criteria for Adverse Events (version 4.03). Secondary outcomes were effectiveness of SGM-101 for detection of colorectal cancer, assessed by TBRs, concordance between fluorescent signal and tumour status of resected tissue, 
and diagnostic accuracy. Additionally, the amount of injected SGM-101 that was lost by binding to serum CEA was calculated by measuring serum CEA directly before and after dosing in both cohorts.

\section{Statistical analysis}

Due to the exploratory nature of this study, sample size was not based on statistical power considerations. TBR for fluorescence is reported as mean and SD. Patient characteristics are reported as median and IQR. Fluorescence in tumour and normal tissues, measured on FFPE tissue blocks with the Pearl imager, was compared with the paired, non-parametric $t$ test (ie, Wilcoxon rank test). A p value of less than 0.05 was considered significant. Data are summarised in a bar chart (mean [range]) and box plot (median [IQR]). Patients in the dose-escalation cohort were included in the primary analysis. Patients in the expansion cohort were analysed separately. We did all statistical analyses and generated graphs using GraphPad Prism (version 7.0).

This trial is registered with the prospective Dutch trial registry (Nederlands Trial Register), number NTR5673, and ClinicalTrials.gov, number NCT02973672.

\section{Role of the funding source}

The study was designed by the investigators and approved by the sponsor, Surgimab. The funder of the study had no role in data collection, data analysis, data interpretation, or writing of the report. The corresponding author had full access to all the data in the study and had final responsibility for the decision to submit for publication.

\section{Results}

Between January, 2016, and February, 2017, 26 patients were included in this study. Nine patients were included in the dose-escalation cohort and 17 patients were included in the expansion cohort. In two patients from the expansion cohort, the planned surgery was aborted because of unexpected tumour ingrowth in the anal sphincter in one of the patients who wanted only sphincter-saving surgery, and a high peritoneal carcinomatosis index in the other patient who was planned for cytoreductive surgery with hyperthermic intraperitoneal chemotherapy. Despite abortion of the surgical procedures, fluorescence imaging in the first patient was successfully done via transanal inspection with a laparoscope and in the second patient during exploratory laparotomy. Table 1 summarises the patient characteristics, surgical procedures, and histopathology results.

No serious adverse events were reported in the dose-escalation cohort of patients with primary colorectal cancer. Three possibly related mild adverse events were noted in three $(33 \%)$ of nine patients in the dose-escalation cohort and five possibly related mild adverse events were reported in three $(18 \%)$ of 17 patients in the expansion cohort. In the expansion cohort, five moderate adverse events were reported in three $(18 \%)$ of 17 patients that were all regarded

\begin{tabular}{|c|c|c|c|c|c|c|}
\hline & System organ class & Preferred term & Severity & $\begin{array}{l}\text { Serious } \\
\text { adverse } \\
\text { event }\end{array}$ & $\begin{array}{l}\text { Relationship } \\
\text { to SGM-101 }\end{array}$ & Occurrence \\
\hline \multicolumn{7}{|c|}{ Dose-escalation cohort } \\
\hline \multicolumn{7}{|c|}{$5 \mathrm{mg}$ of SGM-101 } \\
\hline \multicolumn{7}{|l|}{ Patient 1} \\
\hline Day 3 & $\begin{array}{l}\text { Skin and subcutaneous } \\
\text { disorders }\end{array}$ & Scar pain & Mild & No & Unrelated & $\begin{array}{l}\text { Single } \\
\text { occasion }\end{array}$ \\
\hline Day 6 & Gastrointestinal disorders & Paralytic ileus & Mild & No & Unrelated & $\begin{array}{l}\text { Single } \\
\text { occasion }\end{array}$ \\
\hline Day 8 & $\begin{array}{l}\text { General disorders and } \\
\text { administration site } \\
\text { conditions }\end{array}$ & Pyrexia & Mild & No & Unrelated & $\begin{array}{l}\text { Single } \\
\text { occasion }\end{array}$ \\
\hline Day 17 & Gastrointestinal disorders & Proctalgia & Mild & No & Unrelated & $\begin{array}{l}\text { Single } \\
\text { occasion }\end{array}$ \\
\hline \multicolumn{7}{|l|}{ Patient 2} \\
\hline Day 4 & Gastrointestinal disorders & Nausea & Mild & No & Unrelated & $\begin{array}{l}\text { Single } \\
\text { occasion }\end{array}$ \\
\hline \multicolumn{7}{|l|}{ Patient 3} \\
\hline Day 20 & Metabolism & Dehydration & Mild & No & Unrelated & $\begin{array}{l}\text { Single } \\
\text { occasion }\end{array}$ \\
\hline \multicolumn{7}{|c|}{$7.5 \mathrm{mg}$ of SGM-101 } \\
\hline \multicolumn{7}{|c|}{ Patient 4} \\
\hline Day 1 & $\begin{array}{l}\text { Skin and subcutaneous } \\
\text { disorders }\end{array}$ & Rash & Mild & No & $\begin{array}{l}\text { Possibly } \\
\text { related }\end{array}$ & Intermittent \\
\hline Day 5 & Undetermined & SIRS & Moderate & No & Unrelated & $\begin{array}{l}\text { Single } \\
\text { occasion }\end{array}$ \\
\hline Day 6 & Vascular disorders & $\begin{array}{l}\text { Orthostatic } \\
\text { hypotension }\end{array}$ & Mild & No & Unrelated & Intermittent \\
\hline \multicolumn{7}{|l|}{ Patient 5} \\
\hline Day 6 & Gastrointestinal disorders & Nausea & Mild & No & Unrelated & $\begin{array}{l}\text { Single } \\
\text { occasion }\end{array}$ \\
\hline \multicolumn{7}{|c|}{$10 \mathrm{mg}$ of SGM-101 } \\
\hline \multicolumn{7}{|l|}{ Patient 7} \\
\hline Day 1 & Nervous system disorders & Headache & Mild & No & $\begin{array}{l}\text { Possibly } \\
\text { related }\end{array}$ & $\begin{array}{l}\text { Single } \\
\text { occasion }\end{array}$ \\
\hline Day 4 & $\begin{array}{l}\text { Injury, poisoning, and } \\
\text { procedural complications }\end{array}$ & Phlebitis & Mild & No & Unrelated & Intermittent \\
\hline Day 6 & Gastrointestinal disorders & Nausea & Mild & No & Unrelated & $\begin{array}{l}\text { Single } \\
\text { occasion }\end{array}$ \\
\hline \multicolumn{7}{|l|}{ Patient 8} \\
\hline Day 1 & Gastrointestinal disorders & $\begin{array}{l}\text { Abdominal } \\
\text { discomfort }\end{array}$ & Mild & No & $\begin{array}{l}\text { Possibly } \\
\text { related }\end{array}$ & Intermittent \\
\hline Day 6 & $\begin{array}{l}\text { Musculoskeletal and } \\
\text { connective tissue disorders }\end{array}$ & $\begin{array}{l}\text { Muscle } \\
\text { tightness }\end{array}$ & Mild & No & Unrelated & $\begin{array}{l}\text { Single } \\
\text { occasion }\end{array}$ \\
\hline \multicolumn{7}{|l|}{ Patient 9} \\
\hline Day 1 & $\begin{array}{l}\text { Musculoskeletal and } \\
\text { connective tissue } \\
\text { disorders }\end{array}$ & $\begin{array}{l}\text { Finger } \\
\text { deformity }\end{array}$ & Mild & No & Unrelated & $\begin{array}{l}\text { Single } \\
\text { occasion }\end{array}$ \\
\hline Day 8 & Cardiac disorders & $\begin{array}{l}\text { Atrial } \\
\text { fibrillation }\end{array}$ & Mild & No & Unrelated & $\begin{array}{l}\text { Single } \\
\text { occasion }\end{array}$ \\
\hline Day 9 & $\begin{array}{l}\text { Skin and subcutaneous } \\
\text { disorders }\end{array}$ & Decubitus ulcer & Mild & No & Unrelated & $\begin{array}{l}\text { Single } \\
\text { occasion }\end{array}$ \\
\hline \multirow[t]{2}{*}{ Day 12} & Infections & $\begin{array}{l}\text { Wound } \\
\text { infection }\end{array}$ & Mild & No & Unrelated & $\begin{array}{l}\text { Single } \\
\text { occasion }\end{array}$ \\
\hline & & & & \multicolumn{3}{|c|}{ (Table 2 continues on next page) } \\
\hline
\end{tabular}




\begin{tabular}{|c|c|c|c|c|c|c|}
\hline & System organ class & $\begin{array}{l}\text { Preferred } \\
\text { term }\end{array}$ & Severity & $\begin{array}{l}\text { Serious } \\
\text { adverse } \\
\text { event }\end{array}$ & $\begin{array}{l}\text { Relationship } \\
\text { to SGM-101 }\end{array}$ & Occurrence \\
\hline \multicolumn{7}{|c|}{ (Continued from previous page) } \\
\hline \multicolumn{7}{|c|}{ Expansion cohort } \\
\hline \multicolumn{7}{|c|}{$5 \mathrm{mg}$ of SGM-101 } \\
\hline \multicolumn{7}{|c|}{ Patient 1} \\
\hline Day 3 & $\begin{array}{l}\text { Injury, poisoning, and } \\
\text { procedural complications }\end{array}$ & Scratch & Mild & No & Unrelated & $\begin{array}{l}\text { Single } \\
\text { occasion }\end{array}$ \\
\hline Day 5 & Gastrointestinal disorders & Nausea & Mild & No & Unrelated & Intermittent \\
\hline Day 6 & Vascular disorders & $\begin{array}{l}\text { Scrotal } \\
\text { haematoma }\end{array}$ & Mild & No & Unrelated & $\begin{array}{l}\text { Single } \\
\text { occasion }\end{array}$ \\
\hline Day 12 & Gastrointestinal disorders & Paralytic ileus & Moderate & Yes & Unrelated & $\begin{array}{l}\text { Single } \\
\text { occasion }\end{array}$ \\
\hline Day 15 & Infections & $\begin{array}{l}\text { Urinary tract } \\
\text { infection }\end{array}$ & Mild & No & Unrelated & $\begin{array}{l}\text { Single } \\
\text { occasion }\end{array}$ \\
\hline Day 23 & $\begin{array}{l}\text { Injury, poisoning, and } \\
\text { procedural complications }\end{array}$ & Renal injury & Moderate & Yes & Unrelated & $\begin{array}{l}\text { Single } \\
\text { occasion }\end{array}$ \\
\hline \multicolumn{7}{|c|}{$7 \cdot 5 \mathrm{mg}$ of SGM-101 } \\
\hline \multicolumn{7}{|c|}{ Patient 2} \\
\hline Day 5 & $\begin{array}{l}\text { General disorders and } \\
\text { administration site } \\
\text { conditions }\end{array}$ & Flank pain & Mild & No & Unrelated & $\begin{array}{l}\text { Single } \\
\text { occasion }\end{array}$ \\
\hline \multicolumn{7}{|c|}{$10 \mathrm{mg}$ of SGM-101 } \\
\hline \multicolumn{7}{|l|}{ Patient 4} \\
\hline Day 6 & Infections & $\begin{array}{l}\text { Urinary tract } \\
\text { infection }\end{array}$ & Mild & No & Unrelated & $\begin{array}{l}\text { Single } \\
\text { occasion }\end{array}$ \\
\hline \multicolumn{7}{|l|}{ Patient 5} \\
\hline Day 28 & Infections & Pyelonephritis & Moderate & Yes & Unrelated & $\begin{array}{l}\text { Single } \\
\text { occasion }\end{array}$ \\
\hline \multicolumn{7}{|l|}{ Patient 7} \\
\hline Day 1 & Nervous system disorders & Headache & Mild & No & $\begin{array}{l}\text { Possibly } \\
\text { related }\end{array}$ & $\begin{array}{l}\text { Single } \\
\text { occasion }\end{array}$ \\
\hline \multicolumn{7}{|l|}{ Patient 9} \\
\hline Day 7 & Infections & $\begin{array}{l}\text { Urinary tract } \\
\text { infection }\end{array}$ & Mild & No & Unrelated & $\begin{array}{l}\text { Single } \\
\text { occasion }\end{array}$ \\
\hline \multicolumn{7}{|l|}{ Patient 11} \\
\hline Day 8 & Infections & Pneumonia & Moderate & Yes & Unrelated & $\begin{array}{l}\text { Single } \\
\text { occasion }\end{array}$ \\
\hline Day 19 & Infections & Abscess & Moderate & Yes & Unrelated & $\begin{array}{l}\text { Single } \\
\text { occasion }\end{array}$ \\
\hline \multicolumn{7}{|c|}{ Patient 13} \\
\hline Day 1 & Gastrointestinal disorders & $\begin{array}{l}\text { Abdominal } \\
\text { discomfort }\end{array}$ & Mild & No & $\begin{array}{l}\text { Possibly } \\
\text { related }\end{array}$ & Intermittent \\
\hline Day 1 & Vascular disorders & Dizziness & Mild & No & $\begin{array}{l}\text { Possibly } \\
\text { related }\end{array}$ & $\begin{array}{l}\text { Single } \\
\text { occasion }\end{array}$ \\
\hline Day 1 & Gastrointestinal disorders & Nausea & Mild & No & $\begin{array}{l}\text { Possibly } \\
\text { related }\end{array}$ & Intermittent \\
\hline \multicolumn{7}{|c|}{ Patient 14} \\
\hline Day 1 & Nervous system disorders & Headache & Mild & No & $\begin{array}{l}\text { Possibly } \\
\text { related }\end{array}$ & $\begin{array}{l}\text { Single } \\
\text { occasion }\end{array}$ \\
\hline
\end{tabular}

unrelated to the dosing of SGM-101 (table 2). The most common serious adverse events were infections (three [60\%] of five events), paralytic ileus (one [20\%]), and pyelonephritis (one [20\%]). No changes in vital signs, electrocardiogram, or laboratory results were found after administration of the maximum dose of $10 \mathrm{mg}$ of SGM-101 in both cohorts.

The molecular weight of CEA is $2 \times 10^{5} \mathrm{Da}$ and SGM-101 is $1.5 \times 10^{5} \mathrm{Da}$. The biggest change in serum CEA concentration before and after dosing was $40 \mu \mathrm{g} / \mathrm{L}$. Considering a circulating blood volume of $5 \mathrm{~L}$, this change means a total circulating amount of $200 \mu \mathrm{g}$ (ie, $1 \cdot 2 \times 10^{20} \mathrm{Da}$ or $6 \times 10^{14} \mathrm{U}$ ). The total amount of injected SGM-101 was $5 \mathrm{mg}$ (ie, $3 \times 10^{21} \mathrm{Da}$ or $2 \times 10^{16} \mathrm{U}$ ). Thus, the amount of SGM-101 lost by binding to circulating CEA was 3\%.

Of the nine patients in the dose-escalation cohort, the first three patients received a dose of $5 \mathrm{mg}$ of SGM-101, administered 2 days before surgery. Because of substantial background fluorescence, probably as a consequence of high concentrations of the tracer in the systemic circulation, the interval between dosing and imaging was prolonged to 4 days. The next three patients received a dose of $7.5 \mathrm{mg}$, administered 4 days before surgery. The mean TBR of the resected specimens was 4.70 (SD 0.99) in the $5 \mathrm{mg}$ dose group compared with $5.70(1.27)$ in the $7.5 \mathrm{mg}$ dose group. Hence, the dose was further increased and the three subsequent patients received a dose of $10 \mathrm{mg}$, resulting in a mean TBR of $6 \cdot 10(0 \cdot 42)$. Separate tumour and background signals per dose group are shown in figure 1A.

Fluorescence imaging was used to detect malignant lesions in three patients with colon adenocarcinomas and six patients with rectal adenocarcinomas, including two pathological complete responders. In four of nine patients, a fluorescent signal arising from the primary tumour could be detected during surgery with a mean TBR of 1.83 (SD $0 \cdot 25$; table 3 ). These signals were all from three colon tumours (figures 2A, 2C) and one rectal tumour that was located near the anal verge and detected with transanal fluorescence imaging (TBR 1.52). The remaining five patients' rectal tumours could not be detected by intraoperative fluorescence imaging of the surgical field. Three of these rectal tumours showed a clear fluorescent signal during ex-vivo imaging of the sliced specimen (figures 3A, 3B). The last two specimens showed no fluorescence, which were confirmed as pathological complete responses by histopathological analysis.

Six metastases were detected with fluorescence imaging (mean TBR 1.74, SD 0.32): four colorectal liver metastases, one lymph node metastasis, and one omental lesion (figures 2B, 2D). All thirteen malignant primary and metastatic lesions showed co-localisation of fluorescence with CEA overexpression and tumour cells (figure 3C). Immunohistochemistry staining of tumour tissues showed that CEA expression was strong in $80-100 \%$ of all tumour cells. Two false-positive fluorescent lesions were identified during surgery (mean TBR 1.62, SD 0 11): one lesion was classified as dysplasia of the urothelial lining of the bladder and one as a 


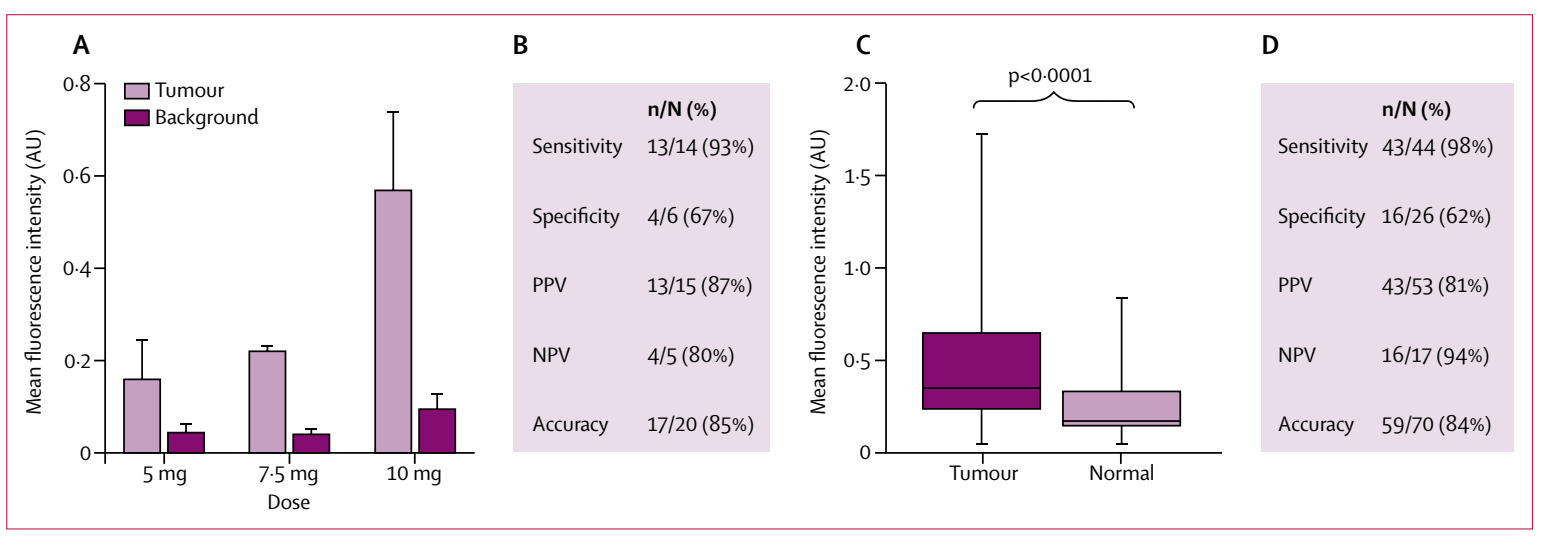

Figure 1: Outcomes of fluorescence imaging in the dose-escalation and expansion cohort

(A) Mean fluorescence intensity of tumour and background tissue per dose group of SGM-101 in the dose-escalation cohort. Error bars are the maximum fluorescence intensity measured. (B) Sensitivity, specificity, PPV, NPV, and accuracy of fluorescence imaging in the dose-escalation cohort. All resected tissues (either detected with visual inspection or with fluorescence imaging) were included in this analysis. (C) Mean fluorescence intensity of all resected lesions in the expansion cohort. On the basis of corresponding haematoxylin and eosin and CEA staining, regions of interest were drawn on fluorescent images and fluorescence between tumour and normal tissues was compared. The horizontal line in the box is the median fluorescence signal. The box refers to $50 \%$ of scores. Error bars are ranges. (D) Sensitivity, specificity, PPV, NPV, and accuracy of fluorescence imaging in the expansion cohort. All resected tissues (either with visual inspection or with fluorescence imaging) were included in this analysis. $\mathrm{AU}=$ arbitrary unit. $\mathrm{N}=$ total number of resected lesions. $\mathrm{PPV}=$ positive predictive value. $\mathrm{NPV}=$ negative predictive value. CEA=carcinoembryonic antigen.

peritoneal lesion consisting of particles of blue ink, caused by perforation of the bowel wall during endoscopic marking of the tumour. None of these lesions displayed CEA expression with immunohistochemistry staining. The diagnostic accuracy is shown in figure 1B.

In the expansion cohort, the first patient received a dose of $5 \mathrm{mg}$ of SGM-101 and the second patient received a dose of $7.5 \mathrm{mg}$, administered 2 days before surgery. The other 15 patients received a dose of $10 \mathrm{mg}, 4$ days before surgery. 44 malignant lesions were resected in 17 patients, of which 43 were fluorescent with a mean intraoperative TBR of 1.64 (SD 0.27 , number of lesions 34; table 3). The non-fluorescent malignant lesion was identified with a random biopsy during intraoperative analysis of a resection margin. Additional histopathological analysis of the part of the rectum where the biopsy was taken showed a microscopic metastasis in the fatty tissue with strong CEA expression.

In the expansion cohort, 19 (44\%) of the 43 malignant lesions were only identified with fluorescence imaging and were not clinically suspected before fluorescent detection. Fluorescence tumour hotspots were located both superficially (eg, tumour spots in the bowel mesentery or ovary) and deeply (eg, retroperitoneal lymph nodes; figure 4); video 13 (68\%) of the 19 lesions were detected in two patients undergoing cytoreductive surgery, followed by hyperthermic intraperitoneal chemotherapy. The other six (32\%) additional malignant fluorescent hotspots were identified in four patients undergoing resection of recurrent colorectal cancer, mostly detected after resection of the tumour specimen at the pelvic wall. The original treatment strategy was altered in six (35\%) of 17 patients because of intraoperative fluorescent detection of additional, otherwise undetected, malignant tissue.

\begin{tabular}{|lcc|}
\hline & In-vivo fluorescence & Ex-vivo fluorescence \\
\hline Dose-escalation cohort & & \\
\hline $\begin{array}{l}\text { Primary tumours } \\
\text { Metastases }\end{array}$ & $4 / 7(57 \%)$ & $6 / 7(100 \%)$ \\
Expansion cohort & $4 / 7(57 \%)$ & $6 / 7(86 \%)$ \\
\hline All lesions & $34 / 44(77 \%)$ & $43 / 44(98 \%)$ \\
Data are $n / N(\%)$, for which N is the total number of resected lesions that were \\
imaged by fluorescence imaging. \\
\hline Table 3: Malignant lesions detected with use of fluorescence imaging \\
\hline
\end{tabular}

Three (18\%) of 17 patients had a pathological complete response after preoperative chemoradiotherapy. In two of these three patients, a fluorescent signal was still identified at the location of the suspected tumour (mean TBR 1.67, SD 0.19). One patient had a tumour mass near the left ovary, which appeared as an abscess during surgery. Both the abscess wall and abscess cavity were fluorescent during surgery, but did not contain malignant cells and were not CEA positive by immunohistochemical staining. The other patient with a pathological complete response had a tumour mass of $24 \mathrm{~mm}$ in diameter near the left iliopsoas muscle, which could be clearly identified during ex-vivo fluorescence imaging. Histopathological analysis revealed extensive necrosis, with mucinproducing cells that were positive for CEA, and scar tissue. Of the 14 patients with a malignancy, 13 had an intestinal-type adenocarcinoma. All these malignancies showed co-localisation of fluorescence and CEA expression on the malignant cells, with strong CEA staining. One patient had a poorly differentiated sarcomatous adenocarcinoma of the sacral bone; although the tumour was fluorescent during ex-vivo imaging (TBR 1.68), no CEA expression was found. 


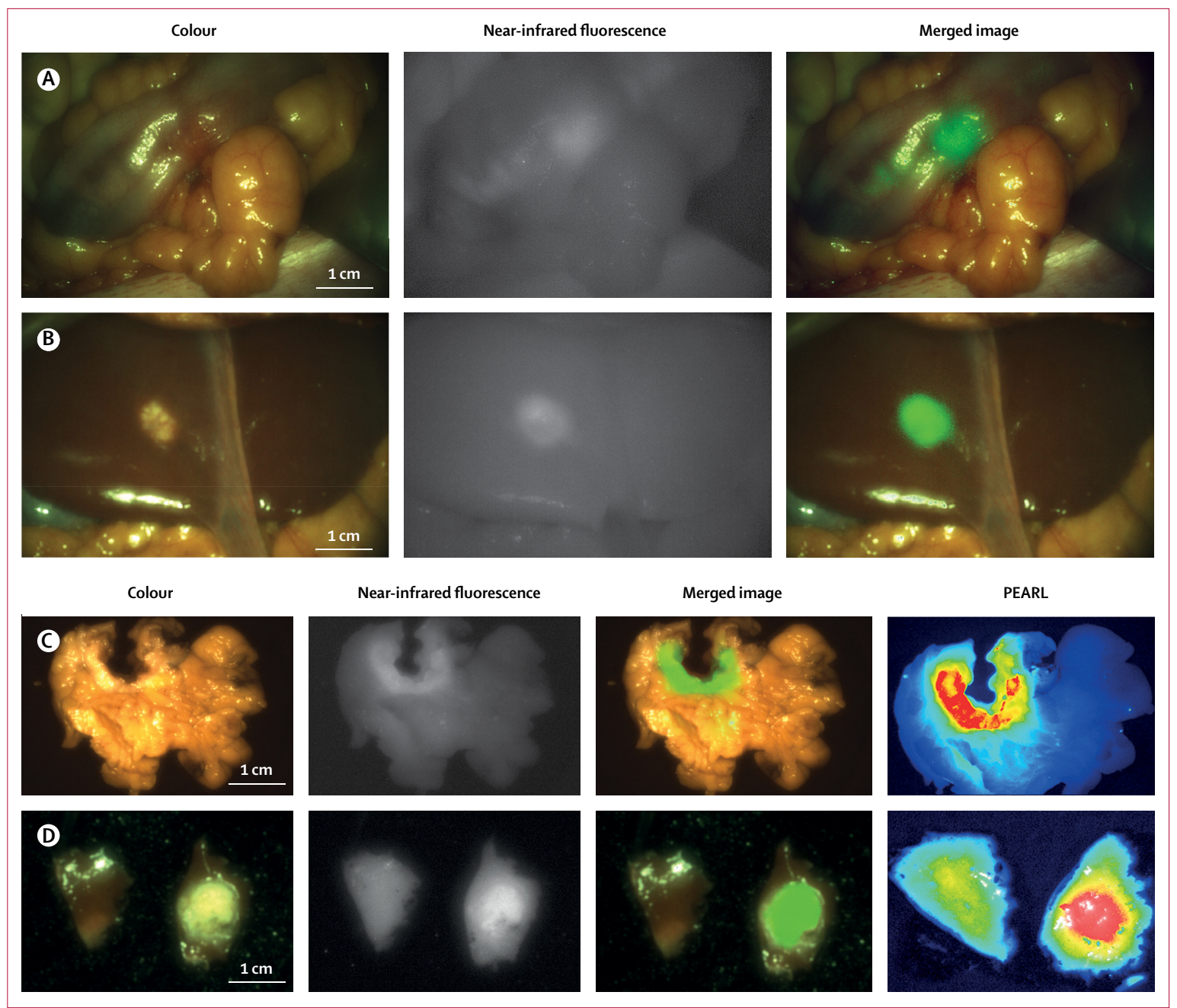

Figure 2: In-vivo and ex-vivo fluorescence imaging of a sigmoid cancer and synchronous liver metastasis

(A) Intraoperative fluorescence imaging resulted in clear fluorescence detection of the primary tumour in the sigmoid. (B) Fluorescence detection of a synchronous liver metastasis. (C) Ex-vivo analysis of the primary sigmoidal cancer. (D) Ex-vivo analysis of the slices containing the liver metastasis, showing co-localisation of fluorescence with visual tumour location.

Ten false-positive lesions were identified with a mean TBR of 1.62 (SD 0.27), including lymph nodes, tissue adhered to the bowel, and at the rectal wall (marked during ex-vivo fluorescence imaging). Some CEA positivity was found in histiocytes within lymph nodes, as well as in fibrotic and chronic inflamed tissue. However, four (80\%) of five assessed false-positive lesions did not show CEA expression. Ex-vivo analysis of FFPE blocks of all resected tissues from the expansion cohort showed a significantly higher fluorescence intensity in tumour tissue than in normal tissue (mean $0 \cdot 51$ [SD 0.43] vs $0 \cdot 24$ [0.19]; $\mathrm{p}<0 \cdot 0001$; figure 1C).

\section{Discussion}

This study shows that intravenous administration of the CEA-specific near-infrared fluorescent tracer SGM-101 is safe, and provides successful detection of primary and recurrent colorectal cancer as well as peritoneal metastases. Intraoperative fluorescence imaging led to detection of otherwise undetected malignant tissue causing the treatment strategy to be altered in about a third of patients. Importantly, SGM-101 did not only identify superficially locate d cancer tissues (eg, small metastases in the omentum or bowel mesentery) but also identified more deeply seeded metastases (eg, retroperitoneal or para-aortic lymph nodes).

CEA is considered a favourable tumour target for colorectal cancer imaging, ${ }^{14,18}$ because it is highly expressed on colorectal cancer tissue, and importantly, expression patterns in rectal cancer are not modified after preoperative chemoradiotherapy. ${ }^{19}$ However, CEA has several disadvantages as a tumour target, including its expression on normal epithelium and the weak anchorage of CEA to the cell membrane. This weak anchorage results in shedding of soluble CEA into the bloodstream, which could serve as a scavenger 
source when injecting a CEA-targeted imaging agent. By measuring serum CEA concentrations in patients before and directly after dosing of SGM-101, we could conclude that $3 \%$ of the administered dose of SGM-101 was lost by binding to circulating CEA. Hence, almost all the injected probe was available for tumour targeting. The upper limit of circulating serum CEA concentration (300 $\mathrm{ng} / \mathrm{mL}$ ) as an exclusion criterion could therefore be abandoned in future studies. Assuming that increased concentrations of serum CEA represent upregulation of this marker in colorectal cancer tissue, serum CEA measurements were initially thought to benefit patient selection. However, a recent study ${ }^{20}$ showed that 32 of 35 rectal cancer tissues showed intense CEA expression independent of the concentration of preoperative serum CEA. In the expansion cohort, this inclusion criterion was therefore adjusted, and patients with increasing serum CEA concentrations since diagnosis were also considered eligible. Although normal expression of CEA on the healthy epithelium could be disadvantageous, this factor did not hinder discrimination between tumour and healthy tissue.

Histopathological analysis showed that some of the false-positive lesions detected contained mucinproducing cells, which express CEA. These lesions were only detected in patients with rectal cancer who had undergone re-irradiation, suggesting a relationship. Future immunohistochemistry studies should clarify the correlation between CEA expression and the subtype of colorectal cancer that contains mucin-producing cells or the effect of re-irradiation, or both. There are several hypotheses about why false-positive lesions appeared fluorescent during surgery. First, although the use of light in the near-infrared spectrum (700-900 nm) is associated with minimal autofluorescence, it is plausible that collagen-rich structures, calcified spots, or the sacral bone could have caused false-positive fluorescence as a consequence of autofluorescence properties. Secondly, the enhanced permeability and retention effect, which results in accumulation of macromolecules (eg, SGM-101) as a consequence of hypervasculature and impaired lymphatic drainage, could play a part in false positivity. ${ }^{21,22}$ This effect is also considered the most likely cause for accumulation of indocyanine green in peritoneal metastases. Indocyanine green is a clinically available near-infrared fluorescent tracer and has been studied for intraoperative detection of peritoneal metastases of colorectal cancer and ovarian cancer. ${ }^{23,24}$ However, this tracer does not specifically bind to tumour cells and, importantly, small peritoneal metastases $(<2 \mathrm{~mm})$ are still avascular and not possible to detect via the enhanced permeability and retention effect. ${ }^{25}$ In an attempt to improve specificity, Harlaar and colleagues ${ }^{6}$ did a pilot study using a VEGF-A-targeting tracer in seven patients undergoing cytoreductive surgery for peritoneal metastases; although a high sensitivity was reported, specificity was only $53 \%$.
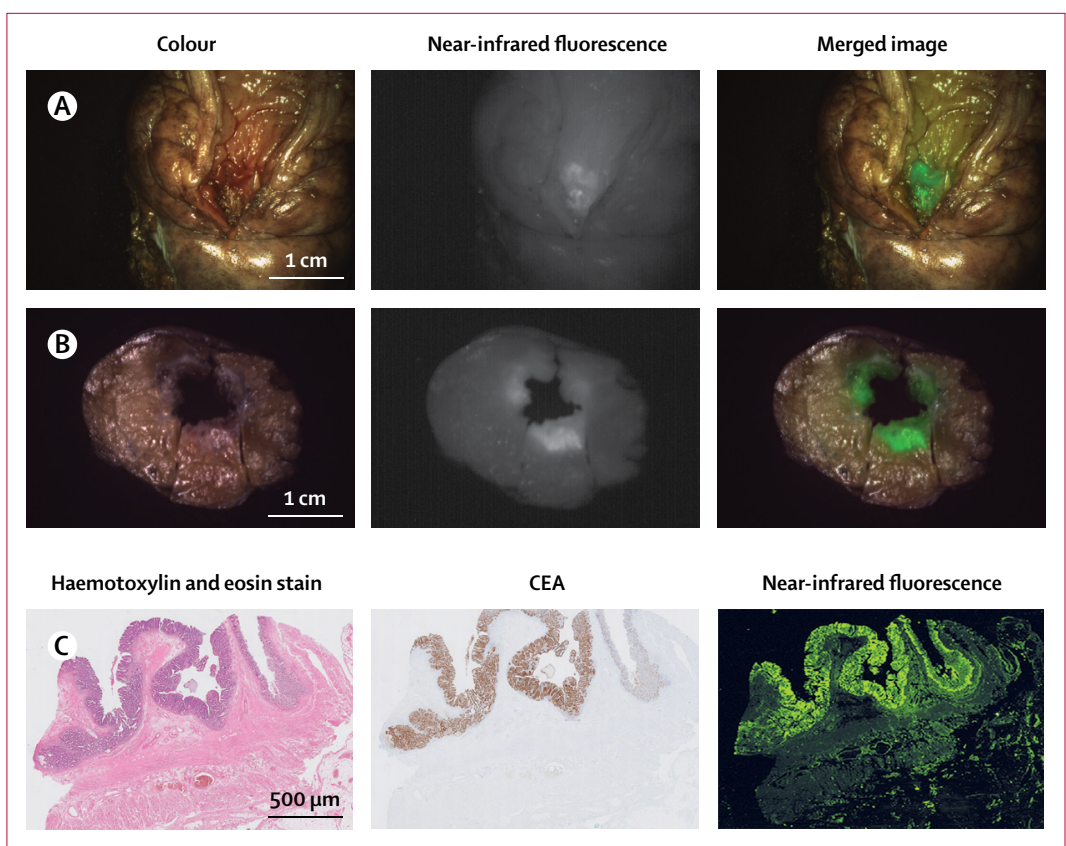

Figure 3: Ex-vivo fluorescence imaging of a primary rectal cancer

(A) In this specimen ( $\mathrm{pT} 2$ ), rectal cancer could not be detected during surgery. After cutting of the specimen, a clear fluorescent signal appeared. (B) Corresponding tumour slice, showing a fluorescence signal on the inside of the rectal wall. (C) Histopathological analysis of a tumour slice, showing co-localisation of tumour cells, CEA expression, and fluorescence. $C E A=$ carcinoembryonic antigen.

The current dose-escalation study was done in patients with primary colorectal cancer. However, in both the dose-escalation and expansion cohorts, the time of administration of SGM-101 between the dosing groups differed-eg, the $5 \mathrm{mg}$ dosing group was done 2 days before surgery, compared with 4 days before surgery in the $7.5 \mathrm{mg}$ and $10 \mathrm{mg}$ dosing groups in the dose-escalation cohort, possibly hampering a fair comparison. Moreover, the maximum tested dose was $10 \mathrm{mg}$ of SGM-101, which did not cause any related adverse events. Higher dose concentrations need to be assessed in upcoming studies to investigate whether higher TBRs can be obtained while maintaining the good safety profile. Furthermore, not all tumours could be intraoperatively visualised. In three patients with rectal cancer and cT1-2 tumours, a fluorescence tumour signal was only visible after slicing of the resected specimen. Although use of near-infrared light allows detection of structures up to $1 \mathrm{~cm}$ in depth, the layer of mesorectum is apparently too thick to penetrate. In our opinion, CEA-targeted fluorescence imaging during colorectal cancer surgery is therefore mainly useful to detect local and distant metastases, as well as locally advanced rectal cancers. Nonetheless, ex-vivo detection of a tumour-specific fluorescent signal underlines the potential added value of SGM-101 during transanal endoscopic microsurgery. Although different optical properties apply to the endoscopic situation compared with ex-vivo fluorescence imaging-eg, scattering and absorption of surrounding tissues-our results suggest 

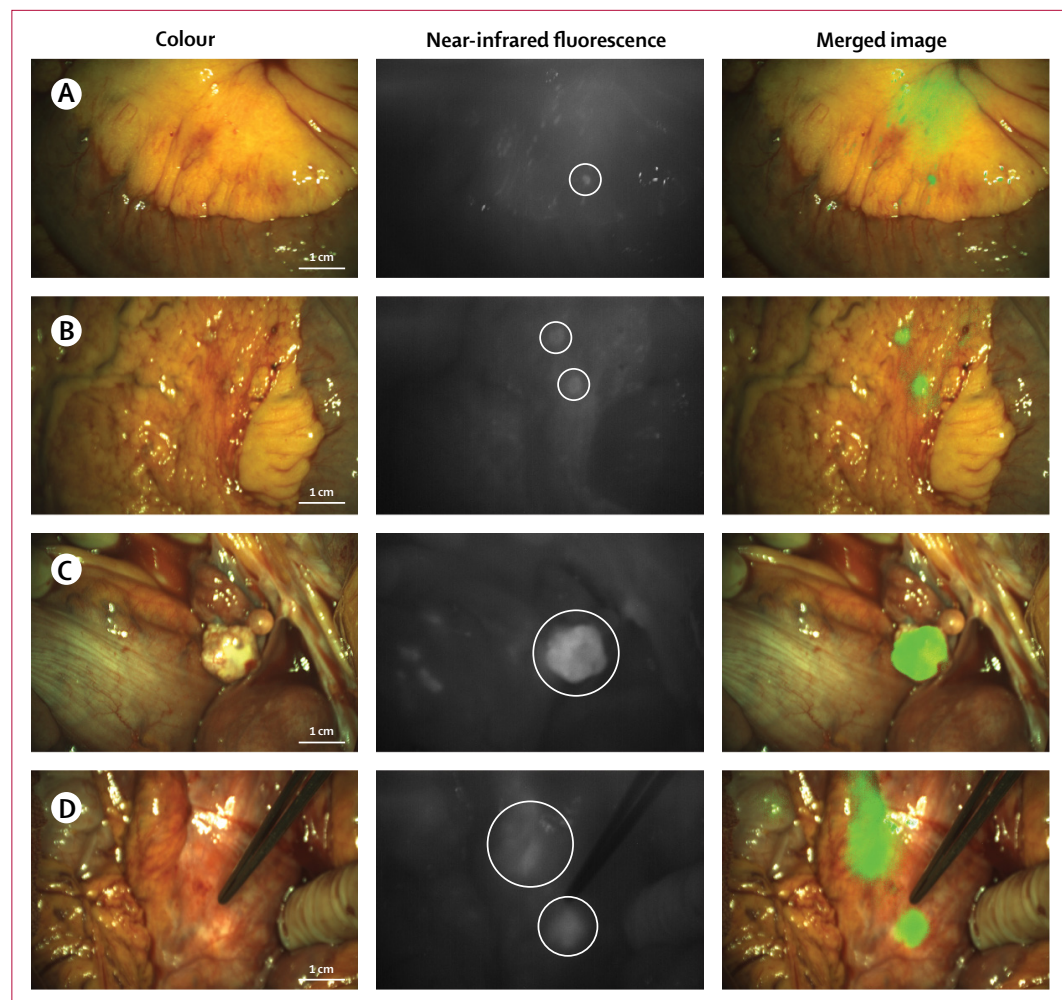

Figure 4: Intraoperative fluorescence detection of additional, otherwise undetected, metastases of colorectal cancer

(A) Identification of a fluorescent hotspot in the bowel mesentery, which was confirmed to contain malignant cells by frozen section analysis. (B) Intraoperative identification of two small additional fluorescent tumour hotspots in the omentum. (C) Intense fluorescence signal shown in the right ovary. Although the surgeon doubted if the ovary contained tumour cells, histopathological analysis revealed involvement of tumour cells. (D) Intraoperative fluorescence detection of retroperitoneal lymph nodes. Even below a layer of overlying tissue, metastasised lymph nodes can still be detected.

that fluorescence imaging could improve the limited sensitivity of endoscopic assessment for residual tumour detection. ${ }^{26}$ The absence of fluorescence in two resected specimens with a pathological complete response underlines the role of SGM-101 application during watch-and-wait strategies after neoadjuvant treatment. ${ }^{27}$

In the expansion cohort, patients with recurrent colorectal cancer and peritoneal metastases of colorectal cancer were included. Although a high sensitivity was reported, ten false-positive lesions were detected. An important lesson to bear in mind is that before substantial resections are done, frozen sections should be taken to ensure that there is no false positivity. SGM-101 can help surgeons to identify areas from which frozen sections should be obtained, which is normally very random without intraoperative imaging. The high negative predictive value indicates that if there is no fluorescence, there is no tumour if it is also clinically unsuspected. However, more deeply seeded tumours can be visualised only when the targeted area is first properly exposed. Targeted dual-modality imaging is currently being investigated to overcome the paucity of depth penetration of near-infrared light.
This technique provides preoperative tumour detection through PET or single-photon emission CT imaging and intraoperative guidance towards deeper located targets via fluorescence imaging and the radioactive label. A recent preclinical study showed accurate preoperative and intraoperative detection of pulmonary micrometastases after intravenous administration of a dual-labelled CEA-targeted antibody. ${ }^{28}$

Although there has been a rapid increase in the number of clinical trials using fluorescence imaging for cancer screening and detection, several barriers must be overcome before the technique can be widely used in everyday clinical practice. ${ }^{2}$ Besides funding and awareness, the translational process of tumour-targeted probes such as SGM-101 is a time consuming process with challenging regulatory affairs. ${ }^{29}$ Most importantly, not all currently available imaging devices have similar detection limits, which results in a scarcity of a fair comparison between these different systems, hampering reproducibility. A potential method to improve intraoperative distinction between malignant and non-malignant tissue might be the use of cutoff values-eg, the use of threshold by calculation of fluorescence with use of phantoms or reference standards. ${ }^{30,31}$ More research is needed to objectively compare imaging devices and to determine the minimal amount of tumour cells that can be detected using a specific device. ${ }^{32}$

In conclusion, we showed that intravenous administration of SGM-101 is safe and provides successful detection of primary, recurrent, and metastasised colorectal cancer, leading to an altered treatment strategy in about a third of patients. Because completeness of tumour resection is associated with increased survival, SGM-101 could potentially improve the clinical outcome of patients undergoing surgery for colorectal cancer, including cytoreductive surgery and hyperthermic intraperitoneal chemotherapy. However, the results from this study have to be interpreted cautiously because of the small population and heterogeneity in doses and timing of fluorescence imaging after dosing. A larger clinical study is needed to assess whether these changes in the operative procedure might influence radical resection rates and completeness of cytoreductive surgery, which should ultimately result in improved local control and overall survival.

\section{Contributors}

LSFB, CESH, DPS, MK, HJMH, MJMvdV, DEH, HJTR, FC, JB, and ALV designed the trial, collected data, and wrote the manuscript. MK, DEH, FAH, KCMJP, JSDM, SWN, IHJTdH, GAPN, HJTR, and ALV did the surgical procedures. IvL and AF-S helped with the histopathological analysis. ALV was the principal investigator. MP, BF, and AP produced the SGM-101, designed the trial, and reviewed the manuscript. CJHvdV designed the trial and reviewed the data and manuscript. All authors reviewed the final version of the manuscript.

\section{Declaration of interests}

The Centre for Human Drug Research (Leiden, Netherlands;

a not-for-profit foundation) and the Leiden University Medical Center (Leiden, Netherlands) received financial compensation, study drug, and equipment for the execution of this study from Surgimab (Montpellier, 
France). FC and BF are employed by Surgimab, which owns the SGM-101 conjugate. FC, AP, and MG are part of the Surgimab founders and are stockholders. All other authors declare no competing interests.

\section{Acknowledgments}

This study was funded by Surgimab (Montpellier, France). We thank all the patients who participated in the study. Additionally, we thank Babs G Sibinga Mulder, Kim S de Valk, and the nurses of the Centre for Human Drug Research (Leiden, Netherlands) for their assistance, as well as Henrica A J M Prevoo and Shadhvi Bhairosingh (Leiden University Medical Center, Leiden, Netherlands) for their assistance with the immunohistochemistry and fluorescence microscopy.

\section{References}

1 Zhang RR, Schroeder AB, Grudzinski JJ, et al. Beyond the margins: real-time detection of cancer using targeted fluorophores. Nat Rev Clin Oncol 2017; 14: 347-64.

2 Tipirneni KE, Warram JM, Moore LS, et al. Oncologic procedures amenable to fluorescence-guided surgery. Ann Surg 2017; 266: 36-47.

3 van Dam GM, Themelis G, Crane LM, et al. Intraoperative tumor-specific fluorescence imaging in ovarian cancer by folate receptor-alpha targeting: first in-human results. Nat Med 2011; 17: 1315-19.

4 Rosenthal EL, Warram JM, de Boer E, et al. Safety and tumor specificity of cetuximab-IRDye800 for surgical navigation in head and neck cancer. Clin Cancer Res 2015; 21: 3658-66.

5 Lamberts LE, Koch M, de Jong JS, et al. Tumor-specific uptake of fluorescent bevacizumab-IRDye800CW microdosing in patients with primary breast cancer: a phase I feasibility study. Clin Cancer Res 2017; 23: 2730-41.

6 Harlaar NJ, Koller M, de Jongh SJ, et al. Molecular fluorescence-guided surgery of peritoneal carcinomatosis of colorectal origin: a single-centre feasibility study. Lancet Gastroenterol Hepatol 2016; 1: 283-90.

7 Nagtegaal ID, Quirke P. What is the role for the circumferential margin in the modern treatment of rectal cancer? J Clin Oncol 2008; 26: 303-12.

8 Gravante G, Hemingway D, Stephenson JA, et al. Rectal cancers with microscopic circumferential resection margin involvement (R1 resections): survivals, patterns of recurrence, and prognostic factors. J Surg Oncol 2016; 114: 642-48.

9 Holman FA, Bosman SJ, Haddock MG, et al. Results of a pooled analysis of IOERT containing multimodality treatment for locally recurrent rectal cancer: results of 565 patients of two major treatment centres. Eur J Surg Oncol 2017; 43: 107-17.

10 Dresen RC, Kusters M, Daniels-Gooszen AW, et al. Absence of tumor invasion into pelvic structures in locally recurrent rectal cancer: prediction with preoperative MR imaging. Radiology 2010; 256: $143-50$.

11 Razenberg LG, van Gestel YR, Creemers GJ, Verwaal VJ, Lemmens VE, de Hingh IH. Trends in cytoreductive surgery and hyperthermic intraperitoneal chemotherapy for the treatment of synchronous peritoneal carcinomatosis of colorectal origin in the Netherlands. Eur J Surg Oncol 2015; 41: 466-71.

12 Sugarbaker PH, Ryan DP. Cytoreductive surgery plus hyperthermic perioperative chemotherapy to treat peritoneal metastases from colorectal cancer: standard of care or an experimental approach? Lancet Oncol 2012; 13: e362-69.

13 Hammarstrom $\mathrm{S}$. The carcinoembryonic antigen (CEA) family: structures, suggested functions and expression in normal and malignant tissues. Semin Cancer Biol 1999; 9: 67-81.

14 Tiernan JP, Perry SL, Verghese ET, et al. Carcinoembryonic antigen is the preferred biomarker for in vivo colorectal cancer targeting. Br J Cancer 2013; 108: 662-67.

15 Boonstra MC, de Geus SW, Prevoo HA, et al. Selecting targets for tumor imaging: an overview of cancer-associated membrane proteins. Biomark Cancer 2016; 8: 119-33.
16 Gutowski M, Framery B, Boonstra MC, et al. SGM-101: an innovative near-infrared dye-antibody conjugate that targets CEA for fluorescence-guided surgery. Surg Oncol 2017; 26: 153-62.

17 van Driel PB, van de Giessen M, Boonstra MC, et al. Characterization and evaluation of the artemis camera for fluorescence-guided cancer surgery. Mol Imaging Biol 2015; 17: 413-23.

18 van Oosten M, Crane LM, Bart J, van Leeuwen FW, van Dam GM. Selecting potential targetable biomarkers for imaging purposes in colorectal cancer using TArget Selection Criteria (TASC): a novel target identification tool. Transl Oncol 2011; 4: 71-82.

19 Boogerd LS, van der Valk M, Boonstra MC, et al Biomarker expression in rectal cancer tissue before and after neoadjuvant therapy. OncoTargets Ther (in press).

20 Boogerd L, Vuijk FA, Hoogstins C, et al. Correlation between preoperative serum carcinoembryonic antigen levels and expression on pancreatic and rectal cancer tissue. Biomark Cancer 2017; 9: 1179299X17710016

21 Maeda H, Wu J, Sawa T, Matsumura Y, Hori K. Tumor vascular permeability and the EPR effect in macromolecular therapeutics: a review. J Control Release 2000; 65: 271-84.

22 Matsumura Y, Maeda H. A new concept for macromolecular therapeutics in cancer chemotherapy: mechanism of tumoritropic accumulation of proteins and the antitumor agent smancs. Cancer Res 1986; 46: 6387-92.

23 Liberale G, Vankerckhove S, Caldon MG, et al. Fluorescence imaging after indocyanine green injection for detection of peritoneal metastases in patients undergoing cytoreductive surgery for peritoneal carcinomatosis from colorectal cancer: a pilot study. Ann Surg 2016; 264: 1110-15.

24 Tummers QR, Hoogstins CE, Peters AA, et al. The value of intraoperative near-infrared fluorescence imaging based on enhanced permeability and retention of indocyanine green: feasibility and false-positives in ovarian cancer. PLoS One 2015; 10: e0129766.

25 Bergers G, Benjamin LE. Tumorigenesis and the angiogenic switch Nat Rev Cancer 2003; 3: 401-10.

26 Kawai K, Ishihara S, Nozawa H, et al. Prediction of pathologica complete response using endoscopic findings and outcomes of patients who underwent watchful waiting after chemoradiotherapy for rectal cancer. Dis Colon Rectum 2017; 60: 368-75.

27 Renehan AG, Malcomson L, Emsley R, et al. Watch-and-wait approach versus surgical resection after chemoradiotherapy for patients with rectal cancer (the OnCoRe project): a propensity-score matched cohort analysis. Lancet Oncol 2016; 17: 174-83.

28 Hekman MCH, Rijpkema M, Bos DL, et al. Detection of micrometastases using SPECT/fluorescence dual-modality imaging in a CEA-expressing tumor model. J Nucl Med 2017; 58: 706-10.

29 Tummers WS, Warram JM, Tipirneni KE, et al. Regulatory aspects of optical methods and exogenous targets for cancer detection. Cancer Res 2017; 77: 2197-206.

30 Burggraaf J, Kamerling IM, Gordon PB, et al. Detection of colorectal polyps in humans using an intravenously administered fluorescent peptide targeted against c-Met. Nat Med 2015; 21: 955-61.

31 Zhu B, Rasmussen IC, Sevick-Muraca EM. A matter of collection and detection for intraoperative and noninvasive near-infrared fluorescence molecular imaging: to see or not to see? Med Phys 2014; 41: 022105

32 Prince AC, Jani A, Korb M, et al. Characterizing the detection threshold for optical imaging in surgical oncology. J Surg Oncol 2017; published online June 19. DOI:10.1002/jso.24733. 